\title{
THE EXPERIENCES OF RACIALIZED FOSTER YOUTH TRANSITIONING OUT OF CHILD WELFARE
}

Afedah Haniff, BSW, York University, 2015

\author{
An MRP \\ Presented to Ryerson University \\ In partial fulfilment of the requirements for the degree of \\ Master of Social Work \\ in the Program of \\ Social Work
}

Toronto, Ontario, Canada, 2019

(C) Afedah Haniff 2019 


\section{AUTHOR'S DECLARATION FOR ELECTRONIC SUBMISSION OF A MRP}

I hereby declare that I am the sole author of this MRP. This is a true copy of the MRP, including any required final revisions.

I authorize Ryerson University to lend this MRP to other institutions or individuals for the purpose of scholarly research

I further authorize Ryerson University to reproduce this MRP by photocopying or by other means, in total or in part, at the request of other institutions or individuals for the purpose of scholarly research.

I understand that my MRP may be made electronically available to the public. 


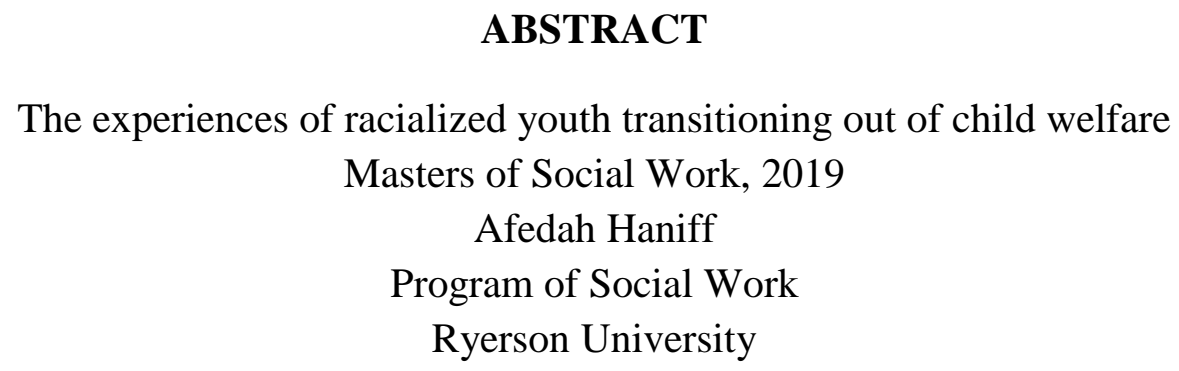

This Major Research Paper investigated the experiences of racialized foster youth transitioning out of the Ontario child welfare system. Utilizing theoretical frameworks of antiBlack racism, anti-colonialism and critical race feminism, this study explores how racism is imbedded in child protection work and the resilience of racialized youth in navigating the complex institutional racism and barriers. The main research question of this study are :1) how do racialized youth describe the treatment they received in foster care as a racialized person? 2) How do racialized youth see themselves navigating society and being independent? The key findings of my study are the following: Lack of financial supports and housing, racism with child welfare, lack of supportive relationships and resilience and advocacy. 


\section{ACKNOWLEDGEMENTS}

I would like to express my sincere appreciation and gratitude to my participant Jane for trusting me to share your narrative; the most valuable, insightful knowledge I have gained from my master of social work was from Jane's participation in this study. Without your contribution, this study would not have been possible. Your resilience and insights are remarkable.

I would also like to acknowledge Dr. Gordon Pon for his ongoing flexibility and support during this process. Your extensive knowledge on the child welfare system and enthusiasm for my research project was greatly appreciated.

I would like to thank everyone that encouraged me to purse my masters of social work. To my family members; thank you for always imparting high expectations upon me and for reminding me of my capabilities and resilience. Most importantly, thank you to all the racialized youth I have worked with within the field for being the source of inspiration for me to pursue my master of social work. 


\section{Content Page}

Introduction

Literature Review

Theoretical Frameworks

Methodology

Findings/Analysis

Implications

Conclusion

References

Appendices
Page \#7

Page \#9

Page \#19

Page \#27

Page \#31

Page \#44

Page \#46

Page \#47

Page \#51 


\section{LIST OF APPENDICIES}

Recruitment Flyer

Consent Agreement

Recruitment Email

Interview Guide

Community Resources

Research Ethics Board Approval
Page \#51

Page \#52

Page \#56

Page \#57

Page \#59

Page \#61 


\section{CHAPTER1: INTRODUCTION}

The research topic for my Major Research Paper (MRP) is the experiences of racialized youth transitioning out of the child welfare system upon adulthood. Central to the experience of youth leaving foster care is a transition to adulthood that is sudden and abrupt. Unlike youth that live with their biological parents, young people who "age out" of foster care no longer receive support irrespective of how prepared they feel for adulthood and transitioning to independent living. It is important to specifically look at the experiences of racialized foster youth as they are often overlooked within research despite being overrepresented in child welfare. The theoretical frameworks that will be used in this study are anti-colonialism, critical race feminism and antiBlack racism. Qualitative research, using a narrative approach will be the research methodology used in this study as this approach will enable me to capture the narrative of racialized foster youth and further explore the institutionalized power of the child welfare system. The major research questions are 1) how do racialized youth describe the treatment they received in foster care as a racialized person? 2) How do racialized youth see themselves navigating society and being independent? This MRP will further explore structural oppression including colonialism and anti-Black racism that may be impacting on the lives of these youth.

Since this MRP is a qualitative study that explores the racialized identity of foster youth leaving care, I reviewed the literature relevant to this topic. Several themes emerged from this literature review which include: 1) social supports 2) housing instability and 3) institutional barriers and racism. Regarding social supports for racialized foster youths leaving care, sub themes of formal and informal mentors, familial support and peer support will be discussed. Institutional racism and structural barriers, specifically the overrepresentation of Black and racialized children and youth within foster care and child welfare at large, will be explored. 
Attaining higher education, obtaining housing and employment are all sub-categories of how success and independent living are taken up within the literature. Finally, means of survival and racialized youth's resilience in navigating adulthood and independent living is another theme that will be further explored within the literature review chapter.

While the overall goal of my MRP is to contribute to on-going knowledge surrounding transitioning out of child welfare, prioritizing the voices of racialized foster youth and their experiences navigating the child welfare system that is heavily imbedded in colonial discourse is also the main focus of this study. I aim to do so by creating a space where voices of racialized foster youth and their narratives of resistance can be heard, especially since racialized experiences within child welfare have been historically silenced. My study aims to contribute to transformative anti-oppressive practice and uncovering the importance of adopting anti-racism and critical race feminism perspectives within child welfare. 


\section{CHAPTER 2: LITERATURE REVIEW}

This chapter presents a review of the literature pertaining to foster youth leaving care. Several key themes emerged from the literature which are the following: social supports, housing instability and institutional barriers and racism.

\section{Social Supports}

Social supports including social networks, peer relationships, mentors, formal supports are all important for foster youth leaving care. However, a major consistent theme throughout the literature indicated that foster youth experienced lack of stability in all aspects of social support. This stems from the instability experienced in foster care. Research has revealed that positive relationships with adults aid in achieving positive developmental outcomes for transitioning youth (Garcia, Pecora, Harachi \& Aisenberg, 2012). While many youth have interacted with numerous counselors, case workers and foster parents, research indicates that foster youth lack lasting, supportive relationships with adults. Relationships built with child welfare workers are often lost due to high case loads within child protection. One of the most significant themes throughout the literature is that foster youth benefit from peer relationships with other youth their age and there is a need for continual social support (Snow, 2008). Instability in relationships with case workers leave children and youth in care feeling unvalued and disposable (Snow, 2008). Studies have pointed to the importance for youth to have supportive adults in their lives as someone they can rely on when making decisions and seeking advice. Experiences of loneliness, lack of belongingness and isolation from non-family figures are a central theme in the lives of foster youth that left care (Sulimani \& Melkman, 2018). African American youth in foster care have more placement instability than their white counterparts and are more likely to be placed in 
congregate care settings, thus impeding their chances of having supportive adults in their lives (Marshall \& Haight, 2014).

\section{Housing Instability}

Lack of stable, adequate housing was a major theme found throughout the literature (Berzin, Singer \& Hokanson, 2014; Geenen \& Powers, 2007; Schelbe, 2018; Sulimani \& Melkman, 2018). Many youth in foster care experience multiple foster placements, triggering frequent changes in foster parents, case workers and schools, thus creating a sense of insecurity and unpredictability (Geenen \& Powers, 2007). This lack of stable, adequate housing is further experienced when youth leave foster care as foster youth struggle with housing issues related to both homelessness and housing stability (Berzin, Singer \&Hokanson, 2014). Research also shows that subsidized housing and independent living programs have been insufficient. For youth in subsidized housing, issues of poor housing conditions, safety, location and access to transportation negatively impact the lives of youth (Schelbe, 2018). Independent Living Programs (ILPs) do not provide individualized transition support that youth need, are not relevant enough to the real world settings and are often insufficient in meeting the transitional needs of youth (Geenen \& Powers, 2007).

Several studies cite youth's unpreparedness for independent living as another issue. Unlike youth that live with their biological parents from whom they could learn from, foster parents are not trained in providing transitional support. Rather the expectation is that foster youth will access programs that provide life skills training. Service providers often report that youth's low self esteem caused their lack of readiness for independent living (Sulimani \& Melkman, 2018). Other studies have found that youth lacked training on life skills including 
completing house hold chores, cooking and managing finances, but youth are nonetheless

resourceful in navigating their precarious circumstances (Schelbe, 2018).

\section{Institutional Barriers and Racism}

Racial and elite bias are central themes in a few studies that focus on the experiences of racialized populations within the child welfare system. Widespread racism puts Black families at risk for precarious employment, lack of adequate housing and poverty, thus increasing their risk for being targeted by child welfare. In a study conducted in 2011, it was found that AfroCaribbean service users and workers experienced racism in the child welfare system in Toronto (Clarke, 2011). Similarly, in a study conducted by Marshall and Haight (2014), it was found that service providers in the youth justice and child protection systems reported that Black youth and families receive harsher treatment when compared to their European American counterparts (2014). Colour blindness existing within law enforcement and child welfare further perpetuate racism experienced by Black, Indigenous and racialized families. Cases receive standard colour blind treatment as issues of racism and white privilege are ignored within child welfare and law enforcement as there is significant resistance to acknowledge power dynamics regarding race and poverty by professionals in these fields. Child welfare workers and law enforcement professionals often do not consider structural and racial barriers but rather individual incidents (Clarke, 2012; Marshall \& Haight, 2014).

Many Black youth also reported surveillance and control while in foster care. Black youth are treated differently by police, social workers and other professionals as they are being constantly monitored and controlled within the foster home and in the community, creating a sense of fear, powerlessness and criminalization (Clarke, 2012). While in foster care, black youth 
have reported being given differential treatment when compared to their white counterparts as they often were more restricted. Resistance towards child welfare staff is another theme experienced by both black foster youth in care and parents involved with child welfare. Because of the negative impact child welfare workers had on the lives of Black youth and families involved, many demonstrate resistance towards workers rules and programs. Youth in foster care show no interest in intervention programs and have been unresponsive to child welfare professionals. Black parents also show resistance when interacting with law enforcement professionals and child welfare staff as they refuse to attend classes and follow through with court orders (Marshall \& Haight, 2014).

Majority of the research literature on my MRP topic are grounded in a constructivist orientation to interpretive paradigm. A constructionist orientation in interpretive paradigm assumes that people construct reality out of their interactions and beliefs (Neuman, 2006). Social reality consists of people constructing meaning and creating interpretations through their daily social interaction (Neuman, 2006). Therefore, the researcher is concerned with the meaning attached to social interactions and experiences. Studying the meaning of social actions and experiences has been explored by various researchers cited for this literature review (Berzin, Singer \&Hokanson, 2014; Geenen \& Powers, 2007; Schelbe, 2008; Sulimani \& Melkman, 2018). The purpose of these research studies varied from understanding the perspectives of the participants on racial disproportionalities among crossover youth ( Marshall \& Haight, 2014), to understanding youth's and service providers' perceptions and experiences about certain programs (Schelbe, 2018) to looking at the experiences and perspectives of Afro-Caribbean service users of child welfare in Toronto (Clarke, 2012). Other studies also seek to explore the perspectives of youth leaving foster care from the perspectives of youth, foster parents and caseworkers within 
child welfare (Geenen \& Powers, 2007) and also foster youth's struggles and strengths (Sulimani \& Melkman, 2018).

Critical race theory is another theoretical framework present in three research studies. Critical race theorists argue that people of colour experience racism in their everyday lives and that White elites shape race relations to serve their own self-interests (Clarke, 2011). In their research study of understanding the perspectives of the participants on racial disproportionalities among crossover youth, Marshall and Haight (2014) use critical race theory in the development and analysis of themes from their data, citing racial resistance from professionals in law enforcement and child welfare to address racism within institutional processes that operate under colour blindness. Similarly, Clarke problematizes the exclusion of Afro Caribbean voices in dominant discourses that tend to highlight the overrepresentation of Black children and youth. Clarke also uses critical race feminism to focus on the gendered and racialized aspects of women's oppression by placing women of color at the center rather than at the margins of analysis, in their analysis, particularly in relation to responses from Black mothers who had child welfare intervention (2012).

While many authors do not identify their theoretical approach and adopt qualitative methodologies, internal inconsistencies in their research makes me argue that positivism was significant theoretical approaches that informed knowledge production based on a number of research studies used in this assignment. While an epistemological position should be congruent with one's methodological approach, this is not always clear in qualitative research (Maiter \& Joseph, 2016). Positivism investigates how external forces, pressures, and structures that operate on individuals, groups, organizations, or societies produce outcomes (Neuman, 2006). It implements standards of knowing that require distancing from the researcher (Hunter, 2002).The 
outcomes positivism is concerned with is a fixed reality experienced by everyone. Individualized responses to oppressions experienced by historically marginalized group are seen as the solution and therefore experiences like mental health and behaviour are often examined. Studies conducted by Garcia et al (2014) examine developmental outcomes measured by experiences of mental health concerns, finishing high school and employment of Latina, African and White foster youth exiting care (2014). Micro solutions including the need of stable relationships, to structural issues related to transitioning out of child welfare for youth are explored in Marion, Paulsen and Goyette (2017). Similarly, Daining and DePanfilis (2007) use very hegemonic, neoliberal ideals of success in measuring "resilience" including educational participation, employment history, avoidance of homelessness, avoidance of early parenthood, avoidance of drug use, and avoidance of criminal activity in their study of foster youth exiting care (2007). Furthermore, this article is a clear example of how harmful master narratives of foster youth being at risk are reinforced within literature and how research can be used to justify oppressive practices within social work. While studies by (Berzin et al) Emerging versus Emancipating: The Transition to Adulthood For Youth in Foster Care use qualitative methods, there are elements of positivist framework witnessed as authors rely on empirical, quantitative studies of emerging adulthood ( Berzin et al, 2014). The epistemological standpoint is that reality can be measured and therefore reliable tools should be obtained. As Neuman (2006) argues, positivist researchers do not necessarily argue causality but rather predictability, i.e. estimating the odds of predictable behaviour (2006).

\section{Strengths and Limitations of Knowledge}

One of the most significant strengths of knowledge produced from a constructivist orientation to interpretivism is that richer, deeper understandings of participant's experiences can 
be derived. In theory, knowledge from this framework can be inclusive as it assumes that reality is experienced differently by people. Deep, rich experiences are recorded verbatim in research findings as seen in some studies (Geenen \& Powers, 2007; Schelbe, 2018). Rich accounts of racialized participants and their experiences of oppression from institutions of child welfare and law enforcement are also seen in other studies (Clarke, 2012; Marshall \& Haight, 2014). Variation in responses youth gave when asked the same questions is evident in a study conducted by Berzin, Singer and Hokanson (2014). This is also seen in the responses from foster youth workers when asked about the effectiveness of independent living programs (ILPs) (Geenen \& Powers, 2007). Furthermore, constructivists uncover that people take the social world around them "for granted" and behave as if the social world were a natural, objective, part of fixed reality (Neuman, 2006). The limitations to the knowledge created from a constructivist orientation to interpretivisim is that although, in order to conduct research from this framework the researcher must spend time and engage with participants, ultimately the interpretation of participants' deep, rich experience that is shared during the research process is left up to the researcher. This is problematic as it reinforces notions of academic distancing and framing the researcher as "the expert". Engaging with participants does not really change their circumstances or experiences of oppression but rather it serves the best interest of the researcher so that some level of trust is gained in order for people to "open up" about their experiences, thus perpetuating vulnerability typically experienced by marginalized populations. Issues of power go unrecognized as reflexivity and positioning one's self is ignored as the researcher is not implicated.

Knowledge created from critical race theory can serve to dismantle racism within institutions and academia as it recognizes Western, colonial, Eurocentric bias. However, often 
issues of gender, patriarchy and binary notions are ignored. Critical race feminism uses intersecting oppressions of race and gender to situate knowledge derived from research. This is evident in Clarke's (2011; 2012) analysis of Afro-Caribbean mothers' experience of control from white women working within child welfare. These theoretical frameworks bring to light issues of cultural assimilation and Western dominance when it comes to effective parenting styles from other cultures being degraded and criminalized. I will discuss critical race theory and critical race feminism in greater detail in the following chapter.

Positivist knowledge maintains the oppression of certain groups of people and validates unequal power relations and privilege within society. This is evident in the way Garcia and colleagues state that African American foster youth are more likely to be diagnosed with a mental health disorder if they did not have access to independent living programs (2012). As authors excluded narratives, the reader is left with the impression that African American youth need to be compliant with programs and also the sense of stigma surrounding mental health is reinforced. Some forms of racial knowledge are used to perpetuate state-sponsored racism through social and economic policies (Hunter, 2002). Similarly, Marion and colleagues reported that $62 \%$ of youth in their study considered their youth worker to be important but this is problematic as there is no depth to understanding participants reality (2012). Since reality is fixed, generalizations are the ultimate product of positivist knowledge. Because positivist researchers are distant, objective outsiders, issues of bias are not even acknowledged much less positioning themselves and being reflexive. 


\section{Discipline, Methods and Methodology}

Psychology plays a huge role in the knowledge created by all the articles cited for this literature review as most of them explore developmental outcomes, mental health, attachment theory and "risky" behaviour. Capitalism also plays a significant role as "success" is often described and positioned by researchers in hetero-normative transitions such as including pursuing higher education, finding employment and getting married, thus maintaining the status quo, and ultimately blaming marginalized population for the oppression they experience. Narrative approaches to qualitative research were employed by numerous studies that used semistructured interviews as their method. Some researchers interviewed participants themselves (Clarke, 2011; 2012; Marshall \& Haight, 2012), while all others hired research assistants and did not have personal contact with participants. Ethnography was used by some authors (Clarke, 2011; 2012; Geenen \& Powers, 2007; Marshall \& Haight, 2012; Schelbe, 2018; Sulimani \& Melkman). Other authors used mixed methods of interviews, observation, questionnaires and measurement scales (Berzin et al.,2014; Garcia et al. ,2014; Marion et al. 2014). Many researchers interviewed foster youth while some specifically interviewed racialized youth, Afro Caribbean foster youth, mothers involved and child welfare staff, Black and White law enforcement and child welfare workers (Clarke, 2011; 2012; Marshall \& Haight, 2012). While narrative, qualitative methods such as interviewing can bring awareness to oppression and marginalization, there are still issues of representation on who is interviewed. Stories we tell of ourselves and that are told of us construct our sense of self; researchers need to be mindful of master narratives their work can produce and the effects it has on populations it regards (Mohr \& Lafrance, 2017).The creation and perpetuation of master narratives is seen throughout almost all of the studies used (excluding Clarke, 2011; 2012; Marshal\& Haight, 2014) as many researchers 
revealed that youth felt unprepared for independent living, lacked financial and life skills, thus justifying the control and micro management other youth expressed in different articles. Furthermore, interview methods are entrenched in Western, individualized practises that isolate marginalized people even further. Also, researchers recruiting youth that are in transitional programs using ethnographic methodology can be problematic when issues of intersecting identities of race, gender, sexual orientation, ability are ignored and also when researchers do not situate themselves appropriately. This can be seen in several studies (Berzin et al. 2014; Garcia et al. 2012; Geenen \& Powers, 2007; Schelbe, 2018). While these mentioned scholars all included racialized foster youth aging out of care, their research questions ignored the impacts of racism, patriarchy, Eurocentrism, colonialism and capitalism. In Lisa Schelbe's (2018) attempt of being reflexive with her participants, they never spoke about white privilege but rather demonstrated white fragility as they spoke about foster youth made "general negative comments about white people" and that their middle class identity made her less privileged (2018). Using questionnaires and scales are also problematic as it tries to minimize people's experiences and instead uses Western practices of labelling while silencing.

Foster youth leaving care experience multiple barriers to success and independent living, as outlined in this literature review. While most studies focus on the struggles and challenges youth face, only a small number of research took into account social location such as race and gender thus strengthen the rationale for this MRP. 


\section{CHAPTER 3: THEORETICAL FRAMEWORKS}

\section{Anti-Black Racism}

Anti-Black racism is the first theoretical framework to be used in this MRP. Anti-Black racism is a structural form of violence, imbedded in colonialism in which racism is directed at Black people and their resistance to such oppression (Phillips \& Pon, 2018). White supremacy is another form of structural violence that works together with anti-Black racism in upholding structural violence against Black people. White supremacy can be described as policies and practices in Canadian settler society that construct white people as patriotic national subjects while devaluing and constructing racial "others" as threats to security and national prosperity (Thobani, 2007). This framework was chosen as there has been an overrepresentation of Black children within Canadian child welfare. In 2015, Toronto Children's Aid Society reported that $41 \%$ of children in care were Black, while Black children only made up $8 \%$ of the city's population (Phillips \& Pon, 2018). Furthermore, Black children are kept in care longer within foster care when compared to children of other backgrounds (Clarke, 2011). Anti-Black racism and white supremacy amplify the effects of white domination and make hyper visible Black suffering. The highly cited overrepresentation of Black children in care but lack of analysis on the whiteness of child welfare as in institution, within the literature further legitimizes intrusive child protection involvement and apprehension experiences by many Black families.

Anti-Black racism can be traced back to the development of the welfare state and child welfare specifically, and is directly situated within the wider narratives of white supremacy, slavery and European expansionism (Phillips \& Pon, 2018). The history of slavery within Canada that existed for three centuries is one that is hidden. This historical erasure of slavery 
from Canada's reputation as a "safe haven" legitimizes violence perpetuated against Black people. Black motherhood has been shaped by the violence inflicted on Black mothers during slavery in which Black mothers endured racial and sexual violence at the hands of slave masters in order to protect their children (Phillips \& Pon, 2018). This history of Black mother's resistance debunks the historical discourse of the Black mother as non-caring, neglectful, nonprotective, and non-nurturing of their children (Phillips \& Pon, 2018). The experiences of Black mothers within child welfare today bare stark similarities with slavery; humiliation utilized by slave masters continue to be used within child welfare as a tactic to discipline Black mothers when they challenge the system and advocate for their children (Phillips \& Pon, 2018).

In order to have a sound understanding of how child welfare is intrinsically connected with Anti-Black racism, the Foucauldian concept of bio-power needs to be explored. Foucault describes the concept of bio-power as the operations of power on individual bodies in order to “optimize its capabilities, efficiency, usefulness, and docility” (Philips \& Pon, 2018). The welfare state, specifically child welfare operates on the basis of this bio-power that is disciplinary in nature and is used to surveille, police, and prosecute Black and racialized people. Anti-Black racism calls attention to the specific laws and practices that led to the segregation in education, housing, and employment experienced by Black people in Canada (James et al., 2010). The rise of the Keynesian welfare state in which Black, indigenous and racialized immigrants were excluded from receiving social entitlements and were further constructed as undeserving while middle class, white hetero-normative nuclear families received these entitlements still has an active legacy in modern social work practice (Thobani, 2007).

Relatively little has changed within the field of child welfare; Black children, youth and parents continue to be marginalized by child welfare as systemic barriers and institutional racism 
are not even considered much less addressed within child protection work. These oppressions are heightened especially as white child protection workers intervene in Black families as this strengthens social construction of white workers as saviours and Black parents as inherently violent, aggressive and in need of policing. Black and racialized children and youth are also dehumanized, demonized and constructed as threats to safety within foster homes and they do not receive the same level of sympathy as white children and youth. As Razack (2010) and Lowe (1996) point out, dominant discourses within society are imbedded in an underlying ontology of forgetting the gruesome legacies of enslavement of Black people and genocide of Aboriginal communities, central to the formation and ascendancy of nations such as Canada and the United States (Pon, Gossine \& Phillips, 2011). This is clearly seen within the institution of child welfare as institutional racism against Black, indigenous and racialized people continue to grow. The inherently racist historical foundation of child welfare along with violent experiences of apprehensions and policing of Black and racialized youth reflect white supremacy, slavery and anti-Black racism. For this reason I chose anti-Black racism, anti-colonialism and critical feminist race theory as frameworks guiding this study.

\section{Anti-Colonialism}

The colonial project and European expansionism are central to the marginalization of Black, indigenous and racialized bodies within child welfare. Historically, the field of social work is one deeply imbedded in colonial practises, white saviour work that operate to uphold white supremacy. Colonialism can be defined as the processes by which the beliefs, values, and practices of the colonizing group are imposed on Indigenous peoples of this land (Hart, Straka \& Rowe, 2017). In the 1400s, European settlers came to Canada with the intention of permanently staying and developing the land. Upon entry into Canada, they found the land to be inhabited by 
indigenous people and used violent means to eradicate indigenous populations in order to conquer land and resources (Smith, 2012). From contaminating indigenous communities with small pox, to the widespread sexual violence inflicted on indigenous women in order to breed new labourers and the mass genocide on the east coast, these gruesome acts of violence committed by white European settlers all shared the common aim of eradicating indigenous populations. This ideology of erasing entire populations in order to fulfill capitalist endeavours is imbedded in white supremacy as genocide is one of the pillars of white supremacy. As Andrea Smith (2012) contends, the logic of genocide holds that indigenous populations are always disappearing, in order to enable non-indigenous peoples' rightful claim to land. The logic of genocide enforced through colonialism and white supremacy is not only limited to physical acts of violence but also encompasses the loss of traditions and erasure of indigenous culture. The 1960s sixties scoop in which aboriginal children were forcefully taken away from their families and placed within the child welfare system was an attempt to eradicate indigenous culture and assimilate them into whiteness and Christianity. Thousands of children in residential care experienced abuse and many children died in care and were never reunited with their families. The residential schools exacted genocide through sexual and physical abuse, purposeful spreading of smallpox, and the eventual death of $50 \%$ of the children in these schools (Henry \& Tator, 2010).

The colonizers taking over the land and placing indigenous people on reserves is another way colonialism works to acquire stolen resources and claim ownership of stolen land. This can also be seen with slavery and how black bodies have been commodified, implying that they are nothing more than property that can be owned by the state. One can easily see that slavery still continues if one looks at bio-power institutions such as prisons and the current prison industrial 
complex (Smith, 2012). The legacy of forced assimilation of hetero-patriarchy, nuclear family and Eurocentric, Christian values is directly tied to child welfare as best standards in parenting are based on these values, forcing racialized bodies to conform in order to avoid harsh consequences. This "need to civilize" historically "othered" groups such as racialized immigrant populations is another tenant of colonialism and further solidifies notions of racialized people as inherently backward and in need of civilization (Smith, 2012).

Apprehension as a child protection practice is a colonial act, clearly situated in displacing Black, indigenous and racialized children and in contemporary times this still remains true. Abuse and neglect run rampant in foster homes as Black, indigenous and racialized children and youth have received second hand treatment. White women social workers continue to target Black, indigenous and racialized families and while Black and indigenous families parenting abilities may have been impacted by intergenerational trauma of slavery and genocide, research along with child protection workers have used this as a means of justifying their heightened involvement with and construction of these groups of people as "at risk" without addressing that the colonial institution of child welfare created this trauma. As seen with indigenous youth who survived residential school, once they left residential schools there were forgotten and later imprisoned by the colonizers as they were left to fend for themselves. This experience of lack of support is nothing new as foster youth are still often forgotten since they are pushed into adulthood and the Westernized practice of independent living.

\section{Critical race feminism}

Critical race feminism addresses the intersecting oppressions of gender, sexism and race many racialized women face (Johnstone, 2018). While critical race feminism has similarities and 
builds upon critical race theory, anti-Black racism and anti-colonialism, it is important to use this perspective especially since white women make up the majority of child protection workers and police racialized parents, typically mothers on their parenting and intimate relationships. According to a 2008 report, 82 percent of the workforce were white, 86 per cent were female, and mostly between 26- 34 years old (Phillips \& Pon, 2008). White saviour feminism is central to the emergence of social work and child welfare in North America. In order to appreciate the use of critical race feminism, one must reflect on the history of social work and the position of white women in social work as gate keepers and agents of the colonial state. Social work, as a profession in Canada was developed in the $20^{\text {th }}$ century, marked by the industrial revolution, transforming the economic, political, and social landscape. New liberal institutions were established during the $19^{\text {th }}$ and $20^{\text {th }}$ centuries in Canada such as the census, the poorhouse, hospitals, and the police, structured around the practice of categorizing the vulnerable and the poor into the deserving and the undeserving (Johnstone, 2018). These white women were characterized by feminist aspirations of female leadership in the political and social realm in combination with a loyalty to British imperialism and the creation of a white settler Canada (Johnstone, 2018). White women became involved in the preservation of whiteness through managing indigenous and immigrant populations, deemed "foreign". The legacy of the sixties scoop carried out by white women in which aboriginal children were forcefully taken from their families and placed in non-indigenous communities has a lasting effect. Today there are three times as many Aboriginal children in care as compared to the height of the Indian residential schools (Phillips \& Pon, 2018).

Equally important and time specific to the $19^{\text {th }}$ and $20^{\text {th }}$ century was the conceptualization of scientific racism by early biologists that coined race with developmental deviations, thus 
justifying notions of superior and inferior human races, as this was seen as scientifically true. From this scientific finding it was then seen that less fit, inferior races were taken to be deviant elements within national populations that had to be either controlled or eliminated so as not to threaten the health of the population as a whole (Johnstone, 2018). Racialized families, specifically Black and indigenous mothers and especially single mothers, have been historically demonized and labelled as bad mothers with poor parenting skills. The policing of racialized' women's bodies and parenting role from Western ideals of gender and the gold standard of the nuclear family enforced by white women social workers in child protection has been an on-going struggle racialized women faced for centuries. Historically, racialized women have been constructed as morally degenerate, sexually depraved, and endowed with fecundity more animalistic than human. Keeping them out of the country was considered a special priority of immigration policies (Thobani as cited in Phillips \& Pon 2008). Very few South Asian and Chinese women were allowed to immigrate to Canada prior to the 1960s and only single black women were allowed to come to Canada as domestic workers without their families (Johnstone, 2018).

White women social workers have engaged in the colonization and oppression of nonwhite women and their families. In her discussion of exalted national subjects, Thobani (2007) asserts that the rise of the welfare state post WW2 established a new positioning and valuation of white women; specifically those working as social workers within child welfare were seen as embodying feminized virtue of care and compassion that had come to reflect the welfare state. White women have gained global recognition for inventing feminism and social justice of apprehending aboriginal children from their impaired mothers, policing aggressive black 
mothers, and rescuing immigrant children from their patriarchal violent culture while their enacting of violence against non-white populations remain unrecognized.

Anti-Black racism, anti-colonialism and critical race feminism were all chosen as theoretical frameworks for this study as it uncovers how race relations of power and oppression and white feminism within child welfare operate on a both individual and policy level of intervention. These theoretical frameworks are directly related to the experience of the participant as a racialized individual. 


\section{CHAPTER 4: METHODOLOGY}

\section{Research Question}

Focussing on the stories of racialized youth transitioning out of child welfare, this MRP investigated the colonial roots and structural racism that typically make the experience of racialized foster youth different than their white foster counterparts. The main research questions for this study are the following: 1) How do racialized youth who are transitioning out of foster care describe the treatment they received in foster care as a racialized person? 2) How racialized youth who are transitioning out of foster care navigate society and being independent?

Ultimately, the motivation behind asking these questions was to acknowledge that racialized youth may be at risk for experiencing racism within the institution of child welfare. Furthermore, I chose these questions in order to uncover how one's identity as a racialized foster youth leaving care has an impact on their interactions in adulthood.

\section{Approach to Inquiry}

Narrative approach was the methodology used to inform my research as I collected information from former racialized foster youth on their experience within child welfare and while transitioning out. At its core, narrative research is a framework and approach for studying stories, which begins with individuals' lived experiences (Creswell \& Poth, 2018; Fraser \& Jarldon, 2015). Using a narrative approach gave racialized youth a space where they can tell their stories of living within the system and how their identity has been shaped while transitioning out of foster care. My intention is to contribute to ongoing knowledge production within this field while prioritizing the voices of specifically racialized youth that leave foster care as they have historically been exclude from the literature. This study was conducted in collaboration with 
racialized foster youth as they participated in editing their transcription and overall knowledge production from this study. A particularly important function of narrative for social work is its ability to construct understandings of persons and groups; stories we tell of ourselves and that are told of us construct our sense of self (McKenzie-Mohr \& Lafrance, 2017). When racialized foster youth narrated their lived experiences of being in child welfare, their voice create a counter narrative that challenge dominant discourses that construct racialized foster youth as "at risk".

\section{Recruitment and data collection methods}

A qualitative research design was used to gather knowledge for this MRP. Semistructured interviews were conducted with one participant, between the ages of 18-24 who self identified as racialized and had spent at least one year in foster care. The in-person, individual, semi-structured interview lasted between 60-90 minutes long and I used the interview guide that comprised of 20 open ended questions. I audio recorded and then transcribed the interview for the purpose of member checking and further analysis.

In order to obtain participants for this MRP, I reached out to my personal contacts that I have or know of others who have lived within foster care for at least one year and are now living independently and meet the criteria of this study. The participant was selected solely based on meeting this criteria.

\section{Data Analysis}

Thematic analysis of data was used to interpret the interview conducted using line by line coding. Thematic analysis is a method for identifying, analysing, and reporting patterns (themes) within data (Braun \& Clarke, 2006). According to Creswell and Poth (2018), narrative data analysis can be done in multiple ways, "an analysis can be made about what was said (thematically), the nature of the telling of the story (structural), who the story is directed toward 
(dialogic/performance), or using visual analysis of images or interpreting images alongside words" (p. 69). Researchers should also consider not only the content of stories but what also what they accomplish (McKenzie-Mohr \& Lafrance, 2017). The implications of transitioning out of child welfare, specifically for racialized foster youth and their counter narratives of resistance are what this study hopes to highlight. After transcribing the interviews, specific themes were established after reflecting on the literature review and examining the responses the participant gave to each question about their experience. I utilized line by line coding by looking for

phrases, words or expression that are distinct and grouping each of these which later became the themes for the findings chapter of this Major Research Paper.

\section{Risks and Ethical Considerations}

Ensuring the safety, confidentiality and well being of my participant is important to antioppressive, anti-racist research conducted for this MRP. One way in which safety was ensured was by submitting a proposal to the Ryerson Research Ethics Board (REB) for approval. The REB was concerned with issues such as the nature of the questions from the interview guide causing potential feelings of discomfort for participants. In order to mitigate some of the potential risks associated with asking participants about their struggles and barriers with independent living and transitioning out of foster care, a list of resources was made available to the participants should they feel distressed. The participant also had the choice to opt out of answering specific questions and the researcher will support participants in accessing resources if needed. Upon introduction, the researcher of this MRP shared with the participant my work experience with foster youth and my experience with child welfare. My hopes were to use these former experiences to provide a safe, non-judgemental environment for the participant. The risk of racialized foster youth feeling triggered or discomforted was low as they were made aware of 
the topic and subject matter prior to consenting to be interviewed and made their own decision around their involvement with this study. Constraints to confidentiality and my duty to report if a participant shared thoughts of harming themselves or others as well as harm regarding individuals under the age of 18 is outlined in the consent document and this was further discussed with participants prior to the interview.

While there are potential risks involved for participants, this study also has some potential benefits. The participant may feel validation of their experiences and expand their understanding of the child welfare system and how it is imbedded within racial and colonial practices and how the child welfare system sets up barriers for foster youth leaving care. This study can provide the participant with a space to share their lived experiences and providing an opportunity for social workers to learn from their experiences. Overall, the participant will be contributing to the ongoing knowledge production in the field of transitioning out of child welfare. 


\section{CHAPTER 5: FINDINGS}

\section{The Participant}

One participant was recruited and interviewed for this MRP. The participant will be referred to as Jane throughout this MRP for confidentiality reasons. Jane is a 24 year heterosexual woman who identifies herself as South Asian. Jane was born in Canada and describes herself as first generation South Asian. She shared that her biological parents immigrated to Canada in the 1990s and were born in Pakistan. Jane shared that she came into care at the age of 10 years old and was shuffled from multiple foster homes and how her racial identity impacted her placement:

"Initially when I came in to care, I used to have access visits but after court that stopped and then when I turn 12 my worker told me that I can get adopted or be in foster care until I turn 18. At 12 years old yeah for sure you have the ability to understand things but it was a huge decision and honestly I didn't really get all the details. I didn't know what questions to ask. I chose adoption because I was tired or being bounced back and forth from different foster homes and even when I finally got adopted at 15, it wasn't all roses. Since my parents did not have any family here (in Canada), kinship wasn't an option for me... and then they wanna be "culturally appropriate" which made it harder for me to get adopted as there aren't much South Asian, much less Pakistani people that want to adopt".

Jane shared her experience transitioning out of care and how for her and many other foster youth, entering adulthood and leaving care is something that she always thought about, unlike youth that live with their biological parents. She spoke about having mixed feelings of relief and nervousness when transitioning out of the system, along with financial challenges:

"For as long as I can remember I was always thinking what next especially after moving between foster homes...when I turned 18 I was like good I'm done with all of this (CAS) but at the same time it was scary knowing I will be out on my own. Since I was really young I already knew how housing is crazy expensive in this city but I didn't know a thing about credit and budgeting. And even though there are services for kids that age out and need support, it's this formalized thing. It's not like for kids who have their parents, 
you can just call your parents or know that if your short on rent you can go home to your parents and your room will still be there."

Finally, Jane spoke about moving out from her adoptive parent's home when she started university and the challenges she faced navigating independent living as a former racialized child in care along with coping strategies she utilized. These challenges and coping strategies will be further discussed in the findings/analysis section of this paper. Currently, Jane works as a financial advisor and hopes to go back to school next year to pursue a Masters degree in project management.

\section{Major Findings}

Using a narrative approach to analyze the findings from the interview, my goal was to "dig deeper" into the lived experience of Jane and how her intersecting identities affected her transition out of foster care to independent living. After transcribing the interview, using thematic analysis, I looked for significant experiences that stood out and were frequently mentioned by the participant. As a result, six themes were generated: 1) financial challenges and housing 2) racism 3) lack of supportive relationships and 4) resilience and advocacy. These themes were intertwined; the challenges Jane experienced all led her to being resistant to systemic oppressions as she was a self advocate and developed resiliency.

\section{Financial Challenges}

Lack of finances and housing was a major theme throughout the study. Financial challenges were tied to lack of information on resources available, lack of financial literacy and the burden of retelling of trauma narratives in order to be deemed deserving of accessing services. Lack of finances and barriers to finding adequate housing were tied to Jane's identity as a South Asian 
woman. Jane also spoke about the struggles her parents faced as immigrants in Canada and how her family was targeted by CAS as they were low income:

"When I was with my parents growing up we didn't have much. My dad worked two jobs and my mom couldn't work because she had some type of surgery back home that basically made her mobility limited but because she was younger and was still able to stand and do some stuff it was like she was not "disabled enough" to get ODSP. I didn't have the sparkly lunch bags other kids have and I didn't have both indoor and outdoor shoes... and when CAS got involved I remember one time I heard the worker telling my mom that she should just buy less groceries. And yeah while there were other (confidential trauma) going on, I do feel like they target poor people."

Inadequate, precarious housing was a major theme that kept coming up during the interview. Jane spoke about the scarcity of affordable housing and how lack of information on how to manage finances put her at risk for precarious housing. Daily living expenses and basic necessities for living were difficult to manage, affecting Jane's ability to concentrate on her academics, practice self-care and have a social life that most youth take for granted.

"I didn't know nothing about budgeting and how to manage my expenses of food, rent, my phone bill, transportation...I used to try to do my groceries and get everything one time because that way I don't waste a token or time. But you don't have a whole lot of time to cook when you're studying and then half of my groceries would go bad. I didn't want to go back to canned and frozen stuff, that tasted like trash...but in the end I had no choice and the grocery store near campus was more expensive than regular ones. While all the other kids would be talking about how they spent their weekend going to the gym and downtown to the club, I just could not relate."

While many young adults enjoy and grow from challenges of independent living for foster youth this is an experience of survival. While there are housing supports and resources available, the process for applying is exhaustive and the waitlist is lengthy. As a result, Jane, like many other youth that age out of the system, co-habituated with roommates as a means to cut costs. : 
"In university, I rented a place like 10 min away from campus and I had roommates but it was just horrible. The kitchen was always a mess, people were always taking my food and it was just toxic. And my room was tiny, only like 3 people max could fit in my room because there was no space. But it was cheap...well not cheap but compared to other places it was less expensive. Then in April the landlord told us that we have to move out and that was before the lease was up because he sold the place. Most of the time, my landlord was nice and a few months he did mention that he was thinking of selling the place but the way he said it didn't sound like he had an actual plan of selling it. Then all of a sudden he tells us we have to move out by the end of the month. I had exams that week and it was so stressful and I just couldn't think. So then I stayed with my best friend and her boyfriend for a few months. I was lucky that they even offered."

However, it was difficult for Jane to accept help from others. She attributes this to her experience in child welfare and how accepting help from others came with conditions and consequences which made it hard for her to trust people:

"At first I was hesitant to take her (best friend) up on her offer because...I didn't want people to feel sorry for me. Like I would think ok what does she want in return? And I feel like growing up in care because everything is formalized with a billion documents...it kind of makes you think twice about who you trust."

While there are some resources and community supports available for foster youth transitioning out of care, youth are still faced with lack of information on resources and are not "given the full picture". Important aspects of finances, credit and loans are left out. Jane touches on this in the following quote:

"The first bank account I opened was a minimum checking account. I had a minimum of like...I don't know I think ten or twelve transactions per month so I thought ok after I reach twelve transactions I wouldn't be able to use my debit card. But of course that was not the case and then when I looked at my account I kept seeing charges to my account. They had told us not to go over your transactions but what the hell does that even mean to a kid getting their own account for the first time? And then with my phone bill they never taught us that we could bargain with the provider...I was in class one day and we didn't have service and one guy was talking about how he beat the price of his phone plan down...that's how I found out." 
Retelling of childhood trauma in order to receive financial supports and resources is another burdening experience former foster youth face when trying to navigate resources. Specifically with post-secondary education, although there is funding available in the form of scholarships, grants and bursaries that are funded by CAS and private donors, former foster youth are forced to retell their stories of childhood trauma and struggle as funding is competitive. This application process is deeply problematic as it retraumatizes youth and promotes negative master narratives:

“...they [CAS] really try to sell this idea that you can create your own future and that being in the system doesn't define you but how can you do that when you're forced to talk about your past all the time? Like when you apply for scholarships those application letters are all about your past."

In another instance, Jane spoke about the long term effects of getting uninformed financial information and how she had to retell her story in order to get pardoned:

"I had some credit card debt and when I finally decided to call my old social worker and she didn't get back to me till after two weeks...not to say it's her fault, I know they got lots of work too. So I told her the situation and she basically told me to tell them about how I was in care and how hard everything's has been...but honestly I didn't want to. They really try to play up the trauma when in fact they (CAS) don't give people proper information and that's why I was in this mess in the first place. They're so many white kids that run up their parent's credit cards and don't have to go through so much crap with the banks. That's why now when I see a brown kid coming into the bank I make sure they understand how interest works and adds up because bad credit can follow you. In the end they reduced the amount I had to pay back but it's like...it's like you have to sell your story to a bunch of strangers which nobody wants to do."

The above quote illustrates not only the long term effects of misinformation, but also how Jane's identity as a racialized youth and experience of lack of information influenced her career path and ensuring young people receive clear information before making financial decisions. This quote also highlights Jane's awareness of the differential treatment and privileges wealthy white 
families have when accessing financial services and how race can be a barrier which will be discussed in greater detail in the next section.

\section{Racism}

Racism was a central theme present throughout the study. In many instances, Jane made reference not only to how her identity as a former youth in care impacted her but also her racialized identity. One of the main research questions this MRP attempted to answer was "how do racialized youth describe their treatment in foster care?" As a racialized youth in care, Jane shared that she experienced racism from the time her family became involved with the system and throughout her stay in foster care. While she was in foster care, Jane spoke about surveillance and how this is experienced by many racialized foster youth:

"You're constantly being watched. Everything is so routine, it's not normal...it's like robotic and god forbid one day you stay out a bit late with your friends the next time the social worker comes you get a whole speech about curfews. One time that happened to me and the lady that adopted me told me that she doesn't want to see me getting involved with drugs and the wrong people. Interestingly enough my high school friends were mainly other brown and black girls and I wonder if I hung out with white kids if she would have the same response if I was out late."

The above quote illustrates how racialized youth in foster care are monitored and how foster parents promote Anti-Black racism as black youth are labelled as "the wrong people". AntiBlack racism and racism at the hands of the child welfare system was not a surprising experience for Jane. As she points out, this is the result of the overrepresentation of white child protection worker and foster parents:

“...when you look at the [child welfare] system many people would just focus on the fact that most parents with [child welfare] involvement are like Native, Black and brown but no one talks about the fact that majority of people working in child welfare are all white. So yes, the entire system is racist. What's more racist that an institution made up of white 
people telling brown and black people they're parenting wrong? They [workers] love to blame parents for the choices they make but they [workers] fail to realize that there's a difference between having choice and making choices out of desperation because you're poor and you don't have many options...they [CAS] can't see the bigger systemic problems because they are a huge part of the problem."

Race neutrality plays a significant role in the overrepresentation of racialized youth in the system as racism and white privilege are ignored. This erasure of race makes it difficult for racism and whiteness to be properly addressed within the child welfare system. Rather, race is trivialized to food and pop-culture icons:

"...you know, in my second foster home, when I introduced myself to the foster lady, and you know my name is super brown and long, she told me that I have a fancy name and asked me if I like samosas and if I like Zayn Malik...I get that she was probably trying to lighten the mood but that is not how you do it...that's how you make someone feel more out of place."

Power and control was a significant sub theme of racism. Jane spoke about power and control not only experienced by racialized foster youth but also racialized families. Unlike white families, many racialized immigrant families not only lack knowledge about the Canadian legal system but their rights are more likely to be violated by law enforcement and bio-power institutions including CAS:

“...you know, it's only recently that I learnt that typically, unless they have sound reason to think that a child is in immediate, serious danger, only then they can interview a kid and if needed apprehend. They're not supposed to talk to your kid without speaking to the parents first. That was definitely not the case for me, they kept me back at school and interviewed me, I was so small and I felt so scared, it was traumatizing...like I was being detained...as much as people place emphasis on educating immigrant families on the legal system over here and their rights, what's to say that knowledge alone is protection? Countless times the rights of racialized people are violated."

While legal aid is available to families with CAS involvement, Jane spoke about the waitlists and how mainly racialized lawyers were more willing to take on pro-bono cases as many racialized 
families cannot afford lawyers on their own. The process itself is stressful and can feel hopeless at times especially for immigrant and refugee families that already feel distrust towards law enforcement officials and government institutions:

"...not like we have much left for legal aide, but when families have CAS involvement they refer you to legal aid if you can't afford a private lawyer...some firms owned by racialized lawyers take on pro-bono cases and that goes to show you the white folks don't care and they are not willing to give up money in order to help racialized people. It makes you think about whose really there to support you...because racialized people get the struggle...those lawyers for sure had to be ten times better to achieve what they got...you can read all you want about racism but it hit different when you experience it yourself"

The above quote speaks to the marginalization lower income immigrant and refugee families further experience at the hands of CAS and the lack of relationality experienced by racialized youth in care which was another theme found within the study. This will be further discussed in the next section.

\section{Lack of Supportive Relationships}

Supportive relationships are essential for youth to have in order to thrive as they transition to adulthood and independent living. From the interview with Jane, it was evident that she experienced isolation within care and did not relate to her workers, foster parents and adoptive parents. She attributes this lack of ability to relate to those around her within foster care to the involuntary nature of coming into care and the treatment she received from workers:

"...I know not everyone's experience in care is going to be the same but for me I just felt like what made it hard for me to really connect with people was the fact that they could have handled the situation better...not so punitive. Yes there were [confidential] issues going on, but they could have dealt with it differently. What made it even harder was seeing other kids being placed with their aunts and uncles and they had cousins but I did not have extended family over here...I feel like the social workers, they feel they know everything; they use their text book analysis and box you into these categories and then when you get a new worker they read what the first worker wrote on CPIN and that forms 
their impression of you...so if you try to challenge your worker, next thing you know you get labelled as "difficult". Obviously they won't tell you that to your face but it's pretty obvious in the way they talk to you...you know they're fake."

This quote shows the importance of building positive relationships with youth in care and how powerful a worker's impressions and assessments can be as it affects the way they and other workers interact with youth. When asked about how past social workers, foster parents and her adoptive parents treated her while in care, Jane spoke about having some supportive foster parents and how systemic issues such as being overworked and lack of support impacted their work:

“...I guess with pretty much any job some people are just there for the paycheque and then there's other people that put their soul into their work...I think it was like my third or fourth foster home...I can't remember which one exactly because I changed so many times...that woman I could actually call a foster mom because she really went out of her way. For the short time I spent with her, I never heard her raise her voice on any of the kids in the home. When I would get upset, she wasn't quick to call me rude or tell me I was disrespectful...she was like the only person that actually said to me that being in care must be so hard and admitted that the system isn't in your favour if you aren't white...that was powerful. The sad part is that there were so many kids in the house and two of them had special needs and it was difficult for her to manage.... and they [foster parents] don't get that much support. Basically even though they are the foster parents, the social worker gives them direction and they only meet like once a month which is pretty crazy when you think of all the issues foster parents have to deal with... when I had to move it was so difficult but I remember she told me that it was not my fault, it was the system's fault for shuffling me around... that touched me because for a long time I blamed myself for everything."

Jane further spoke about the cultural gap of how adulthood is defined within western society and how moving out at a young age does not reflect her cultural values nor the norms of what adulthood and independence looks like:

"Listen, for brown people you're not moving out until you get married...for sure that's another issue by itself but even when people do get married they still have their parents support...that's huge in the South Asian culture... yeah they might not be the best at 
expressing feelings but brown parents they got your back even when you're way past 30 . So for me just the idea of oh you're 18 now, you have to be on your own is pretty bizarre. Family values are pretty strong for us...I have one co-worker she's brown too; she's married in her late thirties and her mother still sends her food and helps her with chores. I know a lot of brown people complain about their parents not really respecting their boundaries...I guess it's a cultural issue but it's a good thing as well sometimes. Like if there's a death in the family no one calls to come over; people show up with food and they help take care of your kids."

Workers having low expectations associated with negatively stereotyping racialized youth made

it difficult for trusting and supportive relationships to be established. Jane explains further:

"building relationships by itself is work and there needs to be trust...it's hard to have good relationships with people who don't believe in you...I still remember my adoptive parents' reaction when I told them that I want to do finance and go to university...they were surprised that I wanted to go to school and they were so patronizing...they kept telling me not to 'pressure myself'; it's almost like they wanted me to choose something easier...like university wasn't at my level; they kept telling me to go to college instead. But I refused... and I got in and I got a scholarship... showed them brown kids are smart too."

Unlike youth that live with their biological parents, foster youth do not have the peace of mind knowing that they can rely on older adults unconditionally. Lack of consistency with workers contributed to this along with the involuntary nature of the people in her life. Jane explained how her experience of being in care motivated her to undertake "creating her family":

"ironic how CAS preaches structure and consistency as parenting goals but they fail to deliver because they shuffle kids around and workers are changing all the time..... when you move out of care, even thought I was adopted it wasn't all rainbows and you don't have someone you can call in the middle of the night if you just need someone to talk to...for sure there are services and crisis lines but it's different. They might for sure care but they're obligated to pick up... When I came out of care it was not easy making friends and meeting people but I pushed myself...I told myself this is the chance I have to create my own family...I reconnected with my parents and now some of my family from back home are here now...it was difficult seeing my parents there were a lot of mixed feeling I had and still have but I'm learning that it's ok to have mixed feelings. I made a few close friends while I was in university and I'm close with people I met through work. It feels 
good to know that the people in my life chose to be there and it's not because it's their job or they're there to get a reference letter."

\section{Resiliency and Advocacy}

Self-advocacy is a skill racialized foster youth develop as a result of being within the child welfare system that limits their ability to make independent decisions. Resiliency and advocating for oneself becomes a survival tactic; questioning decisions, refusal and "non-compliance" were all strategies used to resist CAS control in order to gain some autonomy. Jane shared how she challenged the recommendations of her social worker while in care:

"...she [social worker] always tried to keep pushing me to do counselling, every month she would come and ask me if I considered counselling and my response would always be no...until one time she took me out to eat and asked me again and I was straight up and told her that I'm refusing to answer that question because now it feels like you're forcing me. Then she tried to explain how I have choice and I stopped her right there, I told her that her bringing up counselling every time I saw her was a manipulative tactic - and I used that term purposely - to get me to agree, because if someone keeps telling you no all the time but you still keep asking it's not a matter of oh did you change your mind, its more about lack of respect for my individual choice...she couldn't say anything after that...they [CAS] need to do better than just keep telling people to go for counselling. I went to therapy after I left care and while I got lucky that my therapist is amazing it's not for everyone".

For racialized youth, this also included addressing white privilege and body shaming which is typically unspoken of within child welfare. Jane shared a past experience of when she spoke up for herself:

“...there was a corner store near my high school where a lot of kids used to go get snacks. One day I went to get gum and I had bought chips from the same store a few days ago. My bag was open and you could see the pack of chips and the store owner accused me of stealing it...long story short, in front of the store owner my foster parents defended me but after they actually asked me if I did it. I was furious that they actually thought I would steal a stupid bag of chips....and I was scared too...he was threatening to call cops and have me arrested. When I brought up how for them [foster parents] they would never understand the fear I experienced because I am a dark skinned, tattooed big girl and 
they're white, they got...scared? Because the fact is kids like me aren't even seen as kids or as vulnerable...My foster mom was crying and pretty much guilt tripped me..."

"In high school there was this group of guys that used to make really inappropriate comments about my body and one day it really got to me and I slapped one of them... I got detention; they wanted to suspend me but my foster parents and social worker did advocate for me with the school but behind closed doors they tried to tell me that I needed to lose weight if I didn't want to be a target and they made it all about health...this all came from young white women who eats organic salads and wear Lululemon....and I was not obese, yes, I was probably overweight but nothing concerning. They [social worker and foster parents] were always trying to push me to go see like a nutritionist or a dietitian but I refused."

It is clear that white fragility is an issue racialized foster youth navigate when trying to advocate for themselves. Young racialized women face an added layer of pressure to conform to western standards that associate thin bodies with healthy wellbeing. Navigating the system or "playing the game" was a significant subtheme for racialized youth advocating for their needs. Learning the language and procedures of the system as well as bargaining within the system are essential for racialized youth to be able to receive the resources and supports they need in order to thrive in adulthood. Jane was strategic in making a list of services she needed help with before exiting care:

"There's a lot of good, essential things kids can get from the system but I feel like kids don't know this and foster parents and workers don't really talk about this....and kids don't feel comfortable asking which is sad because they [foster workers] are being paid to provide for you. Before I left [care], CAS paid for driving lessons, I knew to ask for this because even though I wasn't going to be driving or getting a car anytime soon it's expensive."

When talking about self-advocacy, although it is a skill racialized youth need to develop to use when exiting care, it is clear that this is not encouraged within CAS and for racialized youth, any form of challenge posed to workers is perceived as aggressive. Jane demonstrated resiliency in 
finding inspiration from her experience of lack of resources and channeling this through her work as a financial advisor:

"...it's so ironic because they want you to be strong and this word resilient gets thrown around so much but when you do try to speak up next thing you know you know you're aggressive and rude and loud...obnoxious, dramatic I got it all from them [CAS] when in reality I am just simply standing up for myself. The reality is it's not really what I have to say is aggressive or loud or dramatic it's my dark skin and my size. And that goes for everywhere you go in society...you know how many people at the bank think I'm an intern or a receptionist? And when people do find out that I was also in care it's like the shock of their lives because I'm not a statistic. I broke the cycle... and I love what I do. I truly believe knowledge is power especially when it comes to finances. Providing guidance to people on how they use and invest their finances is my way of giving back. When I help young people get [a] mortgage approved, I know I did something right."

Developing resilience and a sense of social responsibility for helping other young people navigating institutions stems from the trauma of growing up in care along with the lack of supportive relationships. For young people that age out of care like Jane, this motivates them to continue working towards their goals and cope with challenges directly. It would be helpful if child welfare valued and welcomed self advocacy instead of treating this as a negative quality in youth. 


\section{CHAPTER 6: IMPLICATIONS}

The implications of this research for future social work practise stems from barriers including systemic racism, trauma and lack of housing racialized foster youth face when transitioning out of care. The barriers and challenges experienced by racialized foster youth uncovered during this study were highly avoidable and highlighted how the child welfare system is rooted in racist, western ideologies that are deeply problematic.

Having access to financial services and resources while transitioning out of care is important for racialized youth to thrive in adulthood. When young racialized people have sustainable housing, this reduces the stress of aging out significantly as being at risk for being homeless becomes lower. Sustaining adequate, secure housing still remains a significant concern for racialized foster youth that places them in precarious situations due to lack of knowledge, lack of abundance and financial constraints. As a result, racialized foster youth end up enduring precarious housing situations that deepen their experience of vulnerability and marginalization. Furthermore, it was identified that lack of knowledge on financial literacy and supports available also negatively impacted racialized foster youth. These findings substantiate the need for child welfare workers to teach youth about the housing market and develop in depth financial literacy skills programs for youth before they transition out of care so that they are well informed and equipped with the tools they need for navigating the system.

This research also indicated that child welfare is largely made up of white staff and there is a severe need for more diverse, racialized staff to be working with young people in care and those transitioning to independent living. As identified by the research participant, the lack of racialized workers and foster parents impact their ability to build trusting relationships and relate 
to each other. Hiring diverse staff that have firsthand experience of racism and a second culture would be a first step towards dismantling the racist foundation child protection is built on. Establishing an organizational culture built on worker's accountability towards youth and developing tools to measure accountability would be beneficial.

Encouraging the development of self advocacy and fostering choice are skills and opportunities that need to be valued within child protection. The research participant spoke about having to retell her story of trauma as an expectation when gaining access to resources such as academic grants and scholarships and how unpleasant this was for her. Forcing racialized youth to create master narratives of trauma in order to gain access to resources prevent them from gaining control of their lives and deepens their sense of lack of control, privacy and distrust for the system. 


\section{CHAPTER 7: CONCLUSION}

The child welfare system has been rooted in displacing Black, Indigenous and racialized families as they are overrepresented within the system. The experience of racialized foster youth transitioning out of care has many layers of intersecting oppressions and privileges. As a racialized woman of immigrant parents, this research study was extremely personal to me as I connected with many aspects of the research participant's narrative of hardship and persistent resistance. Jane's story is a glaring example of how low income new immigrant and refugee families are targeted by CAS for investigations. Her story resonates ith extant studies that have highlighted the strength of racialized foster youth and the cultural gaps that CAS has failed to fill. While Jane has demonstrated great resilience and is now thriving in her adult life, it is important to consider that her success is highly influenced by academic achievements and her decision to pursue post secondary education and a career in the corporate world. While pursuing post secondary education is one avenue to success, the process for applying is lengthy and can be retraumatizing for racialized foster youth, deterring them from this path. Furthermore, it is important to consider that some youth may not be interested in post secondary education and are at a heightened risk of falling through the cracks as CAS does not offer much support to those who do not pursue higher education. Specifically for Black and Indigenous youth that age out, their lived experiences and outcomes will be different than that of other racialized youth due to the legacy of genocide and colonialism enacted against the former by the child protection. 


\section{References}

Berzin, S. C., Singer, E., \& Hokanson, K. (2014). Emerging versus Emancipating: The transition to adulthood for youth in foster care. Journal of Adolescent Research, 29(5), 616-638.

Braun, V., \& Clarke, V. (2006). Using thematic analysis in psychology. Qualitative Research in Psychology, 3(2), 77-101. doi:10.1191/1478088706qp063oa

Carter, S. M. \& Little, M. (2007). Justifying knowledge, justifying method, taking action: Epistemologies, methodologies and methods in qualitative research, Qualitative Health Research, 17(10), 1316-1328.

Clarke, J. (2012). Beyond child protection: Afro-Caribbean service users of child welfare. Journal of Progressive Human Services, 23(3), 223-257. doi:10.1080/10428232.2012.719119

Clarke, J, (2011). The challenges of child welfare involvement for Afro-Caribbean families in Toronto. Children and Youth Services Review, 33(2), 274-283.

Creswell, J.W., \& Poth, C.N., (2018). Qualitative inquiry research design: Choosing among five approaches. Thousand Oaks, CA: Sage.

Daining, C., \& DePanfilis, D. (2007). Resilience of youth in transition from out-of-home care to adulthood. Children and Youth Services Review, 29(9), 1158-1178. doi:10.1016/j.childyouth.2007.04.006 
Garcia, A. R., Pecora, P. J., Harachi, T., \& Aisenberg, E. (2012). Institutional predictors of developmental outcomes among racially diverse foster care alumni. American Journal of Orthopsychiatry, 82(4), 573-584. doi:10.1111/j.1939-0025.2012.01181.x

Geenen, S., \& Powers, L. E. (2007). “Tomorrow is another problem” The experiences of youth in foster care during their transition into adulthood. Children and Youth Services Review, $29,1085-1101$.

Hart, M. A., Straka, S., \& Rowe, G. (2017). Working across contexts: Practical considerations of doing Indigenist/Anti-colonial research. Qualitative Inquiry, 23(5), 332-342.

Hunter, M. (2002). Rethinking epistemology, methodology, and racism: or is White sociology really dead?, Race \& Society, 119-138.

James, C. E., Este, D., Bernard, W. T., Benjamin, A., Lloyd, B., \& Turner, T. (2010). Race and well being: The lives, hopes, and activism of African Canadians. Halifax, NS: Fernwood Publishing.

Johnstone, M. (2018). Settler feminism, race making, and early social work in Canada. Affilia: Journal of Women and Social Work, 33(3), 331-345.

Maiter, S. \& Joseph, A. (2016). Researching racism: The colour of face value, challenges and opportunities, British Journal of Social Work, 0, 1-18.

Marion, É., Paulsen, V., \& Goyette, M. (2017). Relationships matter: Understanding the role and impact of social networks at the edge of transition to adulthood from care. Child and Adolescent Social Work Journal, 34(6), 573-582. doi:10.1007/s10560-017-0494-4 
Marshall, J. M., \& Haight, W. L. (2014). Understanding racial disproportionality affecting African American youth who cross over from the child welfare to the juvenile justice system: Communication, power, race and social class. Children and Youth Services Review, 42, 82-90. doi:10.1016/j.childyouth.2014.03.017

McKenzie-Mohr, s. \& Lafrance, M.N. (2017). Narrative resistance in social work research and practice: Counter-storying in the pursuit of social justice, Qualitative Social Work, 16(2), 189-205.

Neuman, W. L. (2006). The meaning of methodology. In Social research methods: Quantitative and qualitative approaches (6 $6^{\text {th }}$ ed.), (pp79-104). Boston: Pearson Education Inc.

Phillips, D. \& Pon, G. (2018). Anti-black racism, bio-power and governmentality: Deconstructing the suffering of black families involved with child welfare. Journal of Law and Social Policy 28: 81-100.

Pon, G., Gosine, K., \& Phillips, D. (2011). Immediate response: Addressing anti-native and anti black racism in child welfare. International Journal of Child, Youth and Family Studies, $2(3 / 4), 385$

Schelbe, L. (2018). Struggles, successes, and setbacks: Youth aging out of child welfare in a subsidized housing program. Children and Youth Services Review, 89, 298-308. doi:10.1016/j.childyouth.2018.05.005

Smith, A. (2012). Indigeneity, settler colonialism, white supremacy.In HoSang, D., LaBennett, O., \& Pulido, L. (Eds.). (2012).Racial formation in the twenty-first century. Univ of California Press. pp. 66-90. 
Snow, K. (2008). Disposable lives. Children and Youth Services Review, 30(11), 1289-1298.

Sulimani-Aidan, Y., \& Melkman, E. (2018). Risk and resilience in the transition to adulthood from the point of view of care leavers and caseworkers. Children and Youth Services Review, 88, 135 140. doi:10.1016/j.childyouth.2018.03.012

Thobani, S. (2007). Exalted subjects: Studies in the making of race and nation in Canada Toronto: University of Toronto Press. 


\title{
Research \\ Ethics Board
}

University

\author{
Recruitment Flyer \\ Participants needed for a research project... \\ "Experiences of racialized youth transitioning out of foster care"
}

Are you:

- A former Crown Ward or Society Ward that spent at least 1 year within the foster care system?

- Self identify as a person of colour? A person of colour is someone who does not consider themselves to be White or Caucasian (Collins English Dictionary)

- Between the ages of 18-25 years old?

- Now residing on your own without child welfare involvement?

If you answered YES to the above questions you are invited to volunteer in this study to share your experiences and have a voice in the discussion of the difficulty of abruptly exiting care and the racism that exist within the child welfare system.

The purpose of this study is to look at the experiences of racialized youth exiting foster care, the challenges and barriers that they face which stem from the multiple identities they possess, along with the sudden exit from care and how they navigate society while living independently. This research seeks to assess these experiences, relationships and their support system and how these impact the lives of the youth. Interviews will be held in person at a location of your choice that offers privacy or in an office at Ryerson University. Interviews will be audio-recorded and then transcribed. The audio-recording of the interview will be stored in a password-locked device only accessible to Afedah Haniff. 2-3 participants will be recruited for this study.

Your participation will involve 1 interview of 1-2 hours. In appreciation of your time, you will receive a $\$ 10.00$ Wal-Mart gift card and $\$ 6.50$ to cover transportation costs.

Participation in this study is completely voluntary. You may stop participating at any time and you will still be given the incentives and reimbursements described above. If you choose to stop participating, you may also choose to not have your data included in the study and you have two weeks following your withdrawal from the study to advise the researcher. Your choice of 
whether or not to participate will not influence your future relations with Ryerson University or the investigators Afedah Haniff and Gordon Pon involved in the research.

If you are interested in participating in this study or would like more information please contact: Afedah Haniff at afedah.haniff@ryerson.ca . I am a social work student- researcher and this project is part of the requirements to fulfilling my Master of Social Work degree. This research is being supervised by Professor Gordon Pon, MSW, PhD, from the School of Social Work at Ryerson University.

This research study has been reviewed and approved by the Ryerson University Research Ethics Board. REB File \# (2019-029) 


\section{Ryerson University \\ Consent Agreement}

You are being invited to participate in a research study. Please read this consent form so that you understand what your participation will involve. Before you consent to participate, please ask any questions to be sure you understand what is involved if you chose to do this study.

\section{"Experiences of racialized youth transitioning out of foster care"}

INVESTIGATORS: This research study is being conducted by Afedah Haniff, MSW Student, and Gordon Pon, MSW, PhD, from the School of Social Work at Ryerson University.

If you have any questions or concerns about the research, please feel free to contact Afedah Haniff at afedah.haniff@ ryerson.ca .

PURPOSE OF THE STUDY: The purpose of this study is to look at the experiences of racialized youth exiting foster care, the challenges and barriers that they face which stem from the multiple identities they possess, along with the sudden exit from care and how they navigate society while living independently. This research seeks to assess these experiences, relationships and their support system and how these impact the lives of the youth. 2-3 youth participants are being recruited for this study and the eligibility includes being a youth between the ages of 18-25 years old who identifies as having a racialized background and formerly being in care as a Crown Ward, Society Ward or being in foster care for at least 1 year.

This study aims to understand the child welfare system as being imbedded in colonial, Western practices. The study aims to provide racialized youth with a forum for voicing their lived experiences of leaving care and moving into independence. The researcher of this project has had past child welfare involvement. The results of this study will be used for the Major Research Paper of Afedah Haniff in completion of her Master of Social Work degree.

What You Will Be Asked to Do: If you volunteer to participate in this study, you will be asked to do the following things:

- Provide consent (agreement) by signing this form after being informed of confidentiality and the researcher answers any questions or concerns you may have.

- Provide information such as age, ethnicity, education and housing arrangements

- Answer open-ended questions from your own perspective and based on your own experiences. 
Questions may include: What are the barriers/obstacles that you have faced since leaving care? What type of treatment did you receive from foster parents, caseworkers and other professionals while you were in care? How has leaving care affected your life? What could the child welfare system do to help youth transition out of care more successfully?

- Following this interview, you will have up to two weeks to withdraw information that you have provided. There will be no consequences for doing so and your information will be erased immediately.

- The interview should last between 60 - 120 minutes.

- The interview will be held in person at a location of your choice that offers privacy or in an office at Ryerson University.

- After your participation, you can contact Afedah Haniff for any follow-up questions you may have or to access resources for support.

- I will email you a copy of the transcript for you to review. Participants will be provided with 5 days to review the transcript and email me any changes, additions or deletions.

- Upon completion of the research paper the 2 to 3 participants can access the research paper online: https://digital.library.ryerson.ca/

\section{Potential Benefits}

- Contributing to knowledge production and joining the conversation around youth experiences of child welfare.

- You may also feel some degree of validation in being able to share your story and have it contribute to the study.

What are the Potential Risks to you as a Participant: The potential risks of your participation are low however you may experience feelings of discomfort during and after the interview. If you feel uncomfortable during the interview process, you may skip answering a question or stop participation, either temporarily or permanently.

Confidentiality: Only Afedah Haniff, the sole researcher involved with this project will have access to the collected data. The audio-recording of the interview will be stored in a passwordlocked device. The consent form will be stored in the researcher's home in a locked briefcase. After the interviews have been transcribed, pseudonyms will be used and identifying information as well as the audio-recording of the interview will be erased. As the interview will be audio recorded and transcribed, the participant has the right to review and edit the recordings to remove or add information. Participants will receive a copy of the completed study if they would like one. 
The researcher has a responsibility to their "Duty to Report" therefore, if a participant shares information regarding a child under the age of 18 who is at a risk of being harmed or neglected by an adult, the researcher will have to report this information.

Incentives for Participation: The incentive for your participation and time taken to contribute to this study is a $\$ 10.00$ Wal-Mart gift card.

Costs to Participation: There should be no costs to participation as interviews will be scheduled based on mutual availability and your $\$ 6.50$ will be given to each participant cover transportation costs.

Voluntary Participation and Withdrawal: Participation in this study is completely voluntary. You can choose whether to be in this study or not. If any question makes you uncomfortable, you can skip that question. You may stop participating at any time and you will still be given the incentives and reimbursements described above. If you choose to stop participating, your data will be immediately destroyed. However, if you decide to withdraw after two weeks of the interview, your data will not be removed from the study because it will already have been integrated into the overall data analyses. Your choice of whether or not to participate will not influence your future relations with Ryerson University or the investigators Afedah Haniff and Gordon Pon involved in the research.

Questions about the Study: If you have any questions about the research now, please ask. If you have questions later about the research, you may contact: Afedah Haniff, RSW, MSW Student School of Social Work Ryerson University email: afedah.haniff@ ryerson.ca, Gordon Pon, MSW, PhD., Associate Professor School of Social Work Ryerson University 350 Victoria Street Toronto, ON M5B 2K3 Tel. (416) 979-5000 ext.4786 email: g2pon@ ryerson.ca

I , (participant name) have read the above terms and hereby give consent to participate in this study (signature line).

I___ (participant name) consent to audio recording of my information shared during the interview with the primary researcher (signature line).

This study has been reviewed by the Ryerson University Research Ethics Board. If you have questions regarding your rights as a participant in this study please contact: Research Ethics Board c/o Office of the Vice President, Research and Innovation Ryerson University 350

Victoria Street Toronto, ON M5B 2K3 416-979-5042 
Recruitment email

Hello

My name is Afedah Haniff and I am a student researcher at Ryerson University in the Social Work Department. I was also involved in the child welfare system. I am contacting you to see if you may be interested in participating in a research study.

This research is being done as part of my Masters of Social Work degree and my supervisor's name is Gordon Pon. The focus of my research is to look at the experiences of racialized youth transitioning out of foster care, how their identities have influenced the type of treatment they experienced in care, challenges they face abruptly leaving foster care as well as their strengths and resilience in navigating society. 2-3 participants will be recruited for this study.

In order to participate you must be a youth that was either a Crown Ward or Society Ward and you are now living on your own and are no longer involved with child welfare. You must also be between the ages of 18-25 years old and identify as having a racialized background and stayed within foster care for at least one year. A racialized person or a person of colour, is someone who does not consider themselves to be White or Caucasian (Collins English Dictionary)

If you agree to volunteer and be part of this study, you will have one in person interview and be asked open ended questions by the researcher. Your participation will involve meeting with the researcher in person for 1-2 hours for one interview. The interview can take place in an office at Ryerson University or in a place of your choice that gives you some privacy. The information that you provide will be audio recorded and kept confidential. In appreciation of your time, you will receive a $\$ 10.00 \mathrm{Wal}-\mathrm{Mart}$ gift card and $\$ 6.50$ to cover transportation costs.

Your participation is completely voluntary and if you choose not to participate it will not impact your relationship with Ryerson University.

This research project is being done for my Masters of Social Work degree and it has been approved by the Ryerson University Research Ethics Board. REB File \# (2019-029).

If you are interested in more information about the study, please feel free to contact me at afedah.haniff@ryerson.ca

Thank you, Afedah Haniff 


\section{Interview Guide}

My name is Afedah Haniff and I would like to tell you about myself before we start the interview. I knew I wanted to be a social worker after being inspired by a school social worker while I was a high school student. As a woman of colour, I have firsthand understanding of and experience with the subordinate treatment racialized people face in all aspects of society. Furthermore, as a guardian and parental figure to my niece, I know the challenges racialized parents face in raising children in a western society that places value on Eurocentric parenting styles and how racialized families are at risk for child welfare involvement and surveillance. For the past 3 years, I have worked as a Child and Youth Worker and have worked with young people affected by poverty, addictions and mental health and settlement issues. I am sharing this information with you as I understand how difficult it may be to talk about your story. I am here to listen, understand and to provide a space where your voice can be heard without judgement or criticism. There is plenty of information about the overrepresentation of racialized youth in foster care but the voices of racialized youth are significantly lacking. The hope is that this study can help to reduce that gap in literature and more so to reduce the negative labelling racialized foster youth experience. Your participation in this study is completely voluntary and at any time we can pause or stop and you can skip a question if you do not wish to answer it. Following this interview or any time after while the study is being done, you may contact me to request resources for support if something came up for you during this process and I will do my very best to provide that to you. Do you have any questions before we begin?

1. How long have you been out of the care of the child welfare?

2. How old were you when you came into foster care?

3. What is your racial background?

4. What is your ethnic background?

5. What was living in foster care like?

6. How many foster homes did you stay in?

7. How would you describe the treatment you received from foster parents, case workers and other child welfare professionals while you were in care?

8. How did your foster parents assist you in transitioning to adulthood?

9. What are your support systems of adults in your life look like?

10. What are your current living arrangements?

11. How prepared did you feel for independent living?

12. What are some challenges you experienced while leaving foster care?

13. How has leaving care affected your life? 
14. How does your culture define adulthood?

15. How have your experiences living in care and then having to leave care by a certain age impacted your identity and who you are as a person?

16. Have you experienced any racism or sexism in you involvement with the child welfare system?

17. How do you see yourself navigating this world and fitting into society?

18. What could the child welfare system do to help youth transition out of care more successfully?

19. What would help you now and since you left the child welfare system to thrive and manage living on your own?

20. Is there anything that you would like to say to add to this interview? 


\section{Community Resources}

If at any point you are feeling triggered or distressed, you may contact the below community resources. I can assist you in accessing these support services if needed. If you have any further questions, I can be contacted via email at afedah.haniff@ryerson.ca .

Distress Centre: 416-408-4357

Gerstein Centre: 416-929-5200

York Support Services Network: 1-855-310-2673

Toronto Rape Crisis Centre: 416-597-8808

Assaulted Women's Helpline: 416-863-0511

Kid's Help Line: 1-800-668-6868 


\section{Ryerson \\ Research \\ Ethics Board}

University

To: Afedah Haniff Social Work Re: REB 2019-

029: The experiences of racialized youth transitioning out of foster care Date: April 6, 2019

Dear Afedah Haniff,

The review of your protocol REB File REB 2019-029 is now complete. The project has been approved for a one year period. Please note that before proceeding with your project, compliance with other required University approvals/certifications, institutional requirements, or governmental authorizations may be required.

This approval may be extended after one year upon request. Please be advised that if the project $\mathrm{i}$ snot renewed, approval will expire and no more research involving humans may take place. If thi $\mathrm{s}$ isa funded project, access to research funds may also be affected.

Please note that REB approval policies require that you adhere strictly to the protocol as last reviewed by the REB and that any modifications must be approved by the Board before they can beimplemented. Adverse or unexpected events must be reported to the REB as soon as possible withan indication from the Principal Investigator as to how, in the view of the Principal Investiga tor, these events affect the continuation of the protocol.

Finally, if research subjects are in the care of a health facility, at a school, or other institution or community organization, it is the responsibility of the Principal Investigator to ensure that the ethicalguidelines and approvals of those facilities or institutions are obtained and filed with the $\mathrm{R}$ EB prior to the initiation of any research.

Please quote your REB file number (REB 2019-029) on future correspondence.

Congratulations and best of luck in conducting your research.

Dr. Patrizia Albanese, PhD Chair, Ryerson University Research Ethics Board

The Following protocol attachments have been reviewed and approved.

- Recruitment email.docx (submitted on: 17 Jan 2019)

- Community Resources.docx (submitted on: 17 Jan 2019) 
- Consent Form.docx (submitted on: 17 Jan 2019)

- Interview Guide.docx (submitted on: 17 Jan 2019)

- Recruitment Flyer.docx (submitted on: 17 Jan 2019)

- Comments to Chair.docx (1).docx (submitted on: 05 Apr 2019)

- Recruitment email revised.docx (submitted on:05 Apr 2019)

- Recruitment Flyer revised.docx (submitted on: 05 Apr 2019)

- Consent Form revised.docx (submitted on: 05 Apr 2019)

- Interview Guide revised.docx (submitted on: 05 Apr 2019)

- Community Resources revised.docx (submitted on: 05 Apr 2019)

If any changes are made to the attached document throughout the course of the research, an amendment MUST be submitted to, and subsequently approved by the REB. 